\title{
Certificação e circuitos curtos, caminhos possíveis para a sustentabilidade da agricultura familiar? $O$ caso dos produtores de orgânicos do Território Noroeste Paulista \\ Certification and short circuits, possible paths for sustainability family farms? The case of organic producers in the território noroeste paulista
}

\author{
Daniela Capelas Centeno Nakao ${ }^{1}$ \\ Antônio Lázaro Sant'Ana ${ }^{2}$
}

\begin{abstract}
Resumo
O Território Noroeste Paulista é caraterizado por pequenas propriedades, representadas pelo trabalho familiar e cultivo de frutas e hortaliças. A cidade de Jales, integrante do Território, nos últimos anos foi palco de grandes eventos voltados à agricultura orgânica, que estimularam a atuação conjunta dos produtores na busca de formação técnica e comercialização. Este trabalho objetivou investigar o perfil socioeconômico desses agricultores, caracterizar a produção e as formas de comercialização utilizadas. Foram aplicados 13 questionários aos agricultores que possuem propriedades certificadas ou que estão em transição para o sistema orgânico no referido Território. Constatou-se que 76,9\% dos pesquisados são agricultores familiares que têm na produção orgânica sua principal fonte de renda agropecuária, embora haja grandes diferenças, em termos de renda monetária familiar, entre eles. Do total, mais de dois terços possuem certificação orgânica e 84,6\% comercializam diretamente para o consumidor final por meio de um grupo informal, mas um percentual expressivo (38,5\% do total) dos pesquisados depende também dos intermediários para vender parte da sua produção. A diversificação da inserção no mercado, via circuitos curtos, pode se constituir em uma alternativa importante para ampliar a renda das famílias.
\end{abstract}

Palavras-chave: Alimentos orgânicos. Produção. Comercialização. Circuitos curtos. Agricultura familiar.

\begin{abstract}
The Noroeste Paulista Territory is characterized by small properties, represented by family work and fruit and vegetable cultivation. The city of Jales, a component of the Territory, has been in recent years the scene of major events focused on organic agriculture, which stimulated the joint action of producers in the pursuit of technical training and commercialization. This work aimed to investigate the socioeconomic profile of these farmers, characterize the production and the forms of commercialization used. Thirteen questionnaires were applied to farmers who have certified properties or are transitioning to the organic system in the Territory. It was found that $76.9 \%$ of the surveyed are family farmers who have their main source of agricultural income from organic production, although there are large differences in terms of family income between them. Of the total, more than two thirds have organic certification and $84.6 \%$ trade directly to the final consumer through an informal group, but a significant percentage (38.5\% of the total) of those surveyed also depends on intermediaries to sell part of their production. The diversification of market insertion, through short circuits, can be an important alternative to increase household income.

Keywords: Organic food. Production. Commercialization. Short circuits. Family farming.

\footnotetext{
1 Doutoranda em Agronomia na Universidade Estadual Paulista - Júlio de Mesquita Filho (UNESP). E-mail: danielacapelascenteno@gmail.com

${ }^{2}$ Doutor em Sociologia (UNESP). Professor da Pós-Graduação em Agronomia da Universidade Estadual Paulista - Júlio de Mesquita Filho. E-mail: lazaro@agr.feis.unesp.br
} 


\section{Introdução}

Ao mesmo tempo que a agricultura brasileira obteve, a partir da década de 1990, ganhos expressivos de produtividade (GASQUES et al., 2016), também cresceram as preocupações com a sustentabilidade da produção predominante, baseada na utilização de grande quantidade de recursos naturais e energia externos ao sistema agropecuário, sendo que alguns desses insumos causam, frequentemente, poluição e contaminação de solos, da água e do ar, além da possibilidade de deixar resíduos tóxicos nos alimentos.

A agricultura orgânica tem se constituído em uma das formas de contornar esses problemas, pois apesar de sua utilização ainda responder por uma parcela pequena da produção mundial de alimentos, o crescimento acelerado que experimentou, nas últimas décadas, indica que essa forma de produção pode ser uma alternativa socioeconômica viável para os agricultores familiares. No entanto, na América Latina, após quase dobrar a área cultivada entre 2000 e 2009, passando de 3,91 milhões de hectares para 7,66 milhões de hectares, ocorreu uma redução de quase 1 milhão de hectares, chegando a 6,74 milhões de hectares em 2015, embora com muitas variações entre os países da região (RESEARCH INSTITUTE OF ORGANIC AGRICULTURE - FIBL, 2017).

O Território Noroeste Paulista, onde foi a realizada a pesquisa que originou este trabalho, é composto por 36 municípios (Figura 1) que abrangem as microrregiões geográficas (MRG) de Jales e Fernandópolis e dois municípios (Parisi e Meridiano) da MRG de Votuporanga (BRASIL, 2010). A agricultura familiar é bastante importante, abrangendo 9.021 estabelecimentos agropecuários (72,98\% do total). Apesar de se constituírem na maioria em termos de número, em relação à área, os estabelecimentos familiares ocupam 30\% do total (PLURAL, 2011). Especialmente na microrregião de Jales há uma participação importante da fruticultura, com destaque para a uva fina e rústica (uvas finas: Itália e suas mutações como a Rubi, Benitaka e a Brasil; uvas rústicas: Niágara e Isabel), a laranja para mesa e o limão. A olericultura também é expressiva e abastece grande parte do consumo da maioria dos municípios. No referido Território, na última década ocorreu grande expansão dos plantios de cana-de-açúcar, mas a pecuária de corte e de leite também é relevante (SANT'ANA, 2011). 


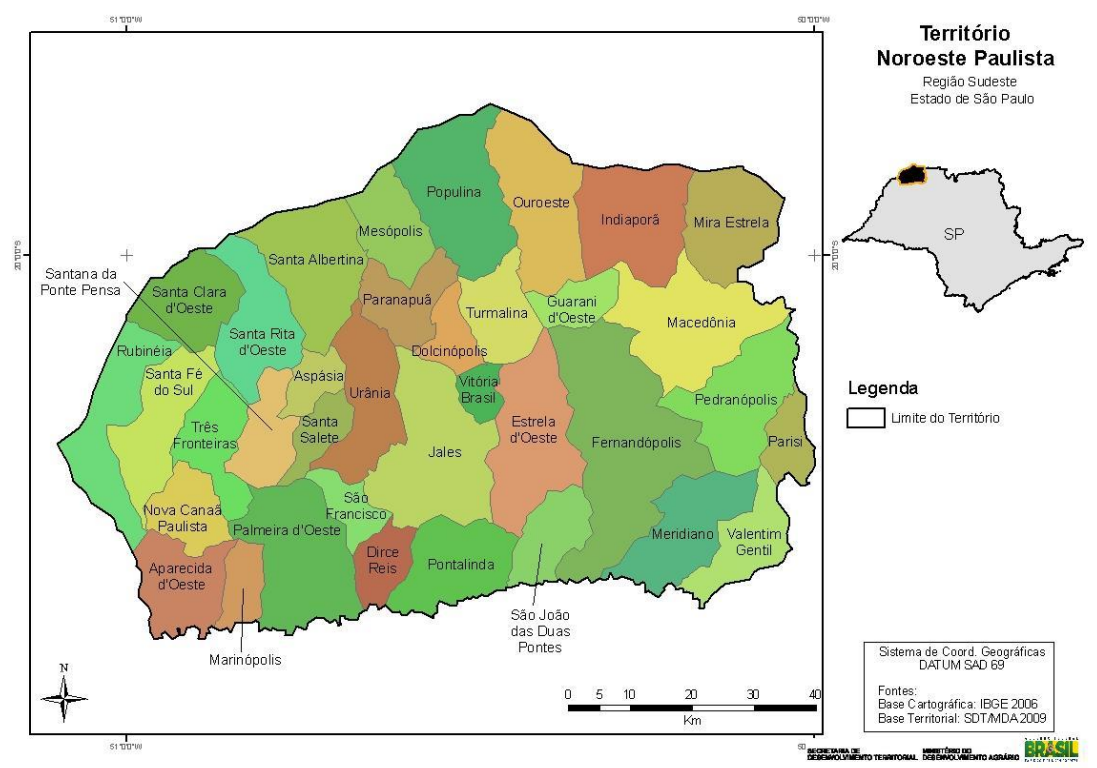

FONTE: BRASIL (2009).

Na cidade de Jales tem se realizado, desde 2014, um importante evento de divulgação da agricultura orgânica, o "Seminário de Agricultura Orgânica do Território Noroeste Paulista", sendo este evento voltado para produtores rurais, engenheiros, técnicos agrícolas, profissionais da saúde, consumidores, estudantes, professores, nutricionistas e outros (CARVALHO, 2017). Em sua terceira edição, em 2017, atraiu mais de 1.000 participantes nos dois dias do evento; em 2019 sofreu um recuo, mas ainda assim contou com aproximadamente 600 participantes.

Como resultado deste evento e do estímulo do Colegiado de Desenvolvimento Rural do Território Noroeste Paulista, um grupo informal de agricultores orgânicos ou em transição passou a se reunir e discutir formas de atuação conjunta, seja em termos de formação técnica ou de comercialização.

Este artigo apresenta e discute os resultados de pesquisa realizada com esse grupo de agricultores e com outros agricultores que possuem propriedades certificadas ou que estão em processo de transição para o sistema orgânico no Território Noroeste Paulista (SP). De maneira específica, visou responder as seguintes questões: como ocorre a produção e a comercialização dos produtos orgânicos no referido Território? Qual é o perfil socioeconômico e a dinâmica de trabalho desses agricultores? Destes agricultores que comercializam orgânicos, quantos são certificados? Quais as formas de inserção no mercado que utilizam e o papel dos circuitos curtos? É possível pensar em estratégias locais para estimular a comercialização em circuitos curtos? 


\section{Metodologia}

No total foram pesquisados 13 agricultores, o que corresponde a 86,6\% dos produtores orgânicos certificados ou em fase de transição orgânica (dentre os dois agricultores não pesquisados, um disse estar deixando a atividade e se recusou a participar; no outro caso, tentou-se várias vezes agendar a entrevista com a produtora, mas sem sucesso), distribuídos nos seguintes municípios do Território Noroeste Paulista: Estrela D’Oeste (1 produtor), Indiaporã (2), Jales (3), Mesópolis (3), Ouroeste (1), Santa Albertina (1), Santa Fé do Sul (1) e Três Fronteiras (1). Nos demais municípios do Território não se constatou a presença de produtores com as características requeridas na pesquisa. Considerou-se como produtores em fase de transição aqueles que já adotaram em seus sistemas produtivos aspectos importantes das regras da produção orgânica, como a não utilização de agrotóxicos e fertilizantes químicos sintéticos.

Além da pesquisa bibliográfica sobre a temática para compor o universo de agricultores pesquisados efetuou-se uma busca de informações sobre o número de produtores orgânicos existentes no Território na Coordenadoria de Desenvolvimento Rural Sustentável (CDRS), antiga Coordenadoria de Assistência Técnica e Integral (CATI), da Secretaria da Agricultura e Abastecimento do Estado de São Paulo. Cabe ressaltar que durante a aplicação da pesquisa, alguns produtores também auxiliaram nas informações, pois indicavam novos produtores de orgânicos.

A etapa seguinte foi constituída por uma pesquisa de campo, que de acordo com Marconi e Lakatos (2010), busca adquirir informações e/ou conhecimentos relativos a um problema, no qual se procura resposta ou uma hipótese, com objetivo de comprovar ou descobrir fenômenos ou relações entre eles. Andrade (2010) relata que este tipo de pesquisa utiliza técnicas específicas como a observação direta e a entrevista, para assim colher e registrar os dados sobre o assunto em estudo.

A pesquisa que originou esse trabalho foi realizada por meio de um questionário, composto por perguntas abertas e fechadas, e aplicado na forma de entrevista (GIL, 2008), com os produtores orgânicos e em transição. Creswell (2010) enfatiza que as questões abertas possibilitam a transformação de dados qualitativos em quantitativos, desde que seja possível contabilizar o número de vezes que o mesmo dado aparece nos textos.

Os principais dados levantados por meio do questionário foram o perfil socioeconômico dos produtores, as características gerais dos estabelecimentos rurais e dos sistemas de produtivos, o destino da produção e a caracterização do processo de comercialização, além de buscar verificar a renda bruta familiar obtida com a produção orgânica. Antes da aplicação do questionário, realizou-se 
um pré-teste, pois segundo Vergara (2010), esse método possibilita julgar e avaliar o formulário, garantindo sua melhor formatação final.

Durante a aplicação do questionário, que ocorreu entre março e agosto de 2017, foram realizadas anotações extras, pois ainda de acordo com Vergara (2010), durante a entrevista é possível, caso o entrevistador autorize, gravar a conversa ou fazer anotações complementares.

Em seguida, foi realizada a tabulação e organização dos dados na forma de tabelas e gráficos, visando à análise e à interpretação dos resultados por meio de estatística descritiva, que segundo Reis e Reis (2002, p. 5) é composta de métodos que são utilizados "para organizar, resumir e descrever os aspectos importantes de um conjunto de características observadas ou comparar tais características entre dois ou mais conjuntos". As ferramentas descritivas envolvem vários "tipos de gráficos e tabelas e também medidas de síntese como porcentagens, índices e médias” (REIS; REIS, 2002, p. 5).

A perspectiva teórica que balizou a construção da abordagem da pesquisa e a interpretação dos resultados foi conceito de estratégias, definidas por Bourdieu (1990, p. 23) como ações que embora "não sejam produto de uma aspiração consciente de fins explicitamente colocados a partir de um conhecimento adequado das condições objetivas, nem de uma determinação mecânica das causas, mostram-se objetivamente ajustadas à situação". O estudo da forma como os agricultores organizam a vida, a produção e a comercialização, com base em suas experiências e nas limitações ou oportunidades da realidade local em que estão inseridos, nos permite compreender as estratégias conscientes (ou não) pelas quais os agricultores familiares buscam sua reprodução social.

\section{Resultados e Discussão}

Em relação ao perfil dos produtores pesquisados, que se apresentaram como responsáveis pelo estabelecimento, constatou-se que 76,9\% são do gênero masculino e 23,1\% do feminino, porém, vale ressaltar que vários produtores estavam acompanhados de suas esposas, que também trabalham na propriedade e participaram das respostas ao questionário. Silva et al. (2017), em sua pesquisa sobre sucessão na agricultura familiar no município de Campos Gerais - MG, relatam uma situação semelhante, em que os questionários foram aplicados em sua maior parte com o casal e mesmo que as respostas tenham sido dadas pelo homem, considerado "chefe de família", as esposas sempre que achavam necessário participavam das respostas.

Quanto à faixa etária dos entrevistados $38,5 \%$ possui 41 a 50 anos de idade, 30,8\% de 31 a 40 anos, $23,1 \%$ de 51 a 60 anos e a apenas 7,7\% (um produtor) tinha até 30 anos. Diante desses dados fica nítida a presença de produtores mais experientes atuando na área de orgânicos, pois o entrevistado 
com menos de 30 anos de idade é filho de produtor e trabalha junto com o pai. Esse perfil de idade é um pouco mais jovem que o encontrado em outras pesquisas com agricultores familiares da região, como a de Sant'Ana (2014), que constatou um percentual de $74 \%$ de produtores com mais de 50 anos, sendo que metade destes apresentavam idade acima de 60 anos.

Embora, na presente pesquisa, a grande maioria desses agricultores esteja em fase plenamente produtiva, o fenômeno do envelhecimento e masculinização da população rural tem se tornado cada vez mais predominante em função da saída dos jovens e, especialmente, das mulheres jovens, como relatam Camarano e Abramovay (1998) e Anjos (2005).

Os agricultores entrevistados possuem, em média, 55 anos; já a idade média observada entre os cônjuges (esposas) foi de 49 anos. Verificou-se, também, que 37\% dos produtores possuem mais de 60 anos, enquanto outros $37 \%$ estão na faixa entre 51 e 60 anos.

Barbé (2009), em sua pesquisa sobre a caracterização dos produtores de orgânicos em Campos dos Goytacazes, também detectou um perfil de idade semelhante, sendo que no caso todos os produtores tinham mais de 30 anos de idade, sendo $40 \%$ de 41 a 50 anos, $30 \%$ de 30 a 40 anos e $30 \%$ possuíam mais de 50 anos. Observa-se, diante desses dados, que predominam os produtores mais experientes atuando na área de orgânicos em ambas as pesquisas.

Verificou-se que 38,5\% dos agricultores possuem Ensino Médio completo, 23,1\% Ensino Superior completo, enquanto apenas 23,1\% Ensino Fundamental incompleto. Observa-se que a maioria dos produtores possui no mínimo o Ensino Médio completo, uma situação diferenciada da média da escolaridade da população brasileira da área rural, que apresenta apenas 4,4 anos de estudo (IBGE, 2014), correspondendo ao Ensino Fundamental incompleto.

Lima (2016), em sua pesquisa com agricultores familiares do noroeste do estado de São Paulo, identificou que a maioria $(50,9 \%)$ possui apenas o Ensino Fundamental incompleto, sendo mais um indício de que os produtores de orgânicos se diferenciam também dos demais quanto à escolaridade.

Em relação à mão de obra total envolvida na produção no estabelecimento (Figura 2), há predominância ( $77 \%$ dos entrevistados) da faixa de duas a quatro pessoas trabalhando na propriedade, enquanto em 23,1\% dos estabelecimentos há cinco ou mais pessoas. Em nenhum caso o trabalho é realizado por apenas um indivíduo. Há uma tendência de diminuição do número de trabalhadores na agricultura em geral, pois como mostra Telles et al. (2017), a População Economicamente Ativa Rural teve uma redução nas Grandes Regiões do Brasil entre 2001 e 2009, com exceção da Região Centro-Oeste. 
Quanto ao número de pessoas da família que trabalham na propriedade, quase a metade $(46,1 \%)$ tem a presença de dois membros, sendo que $84,7 \%$ dos estabelecimentos possuem de dois a quatro membros da família envolvidos na produção.

FIGURA 2 - DISTRIBUIÇÃO PERCENTUAL DOS AGRICULTORES PESQUISADOS EM FUNÇÃO DO NÚMERO TOTAL DE PESSOAS E DO NÚMERO DE FAMILIARES QUE TRABALHAM NA PROPRIEDADE NO TERRITÓRIO NOROESTE PAULISTA

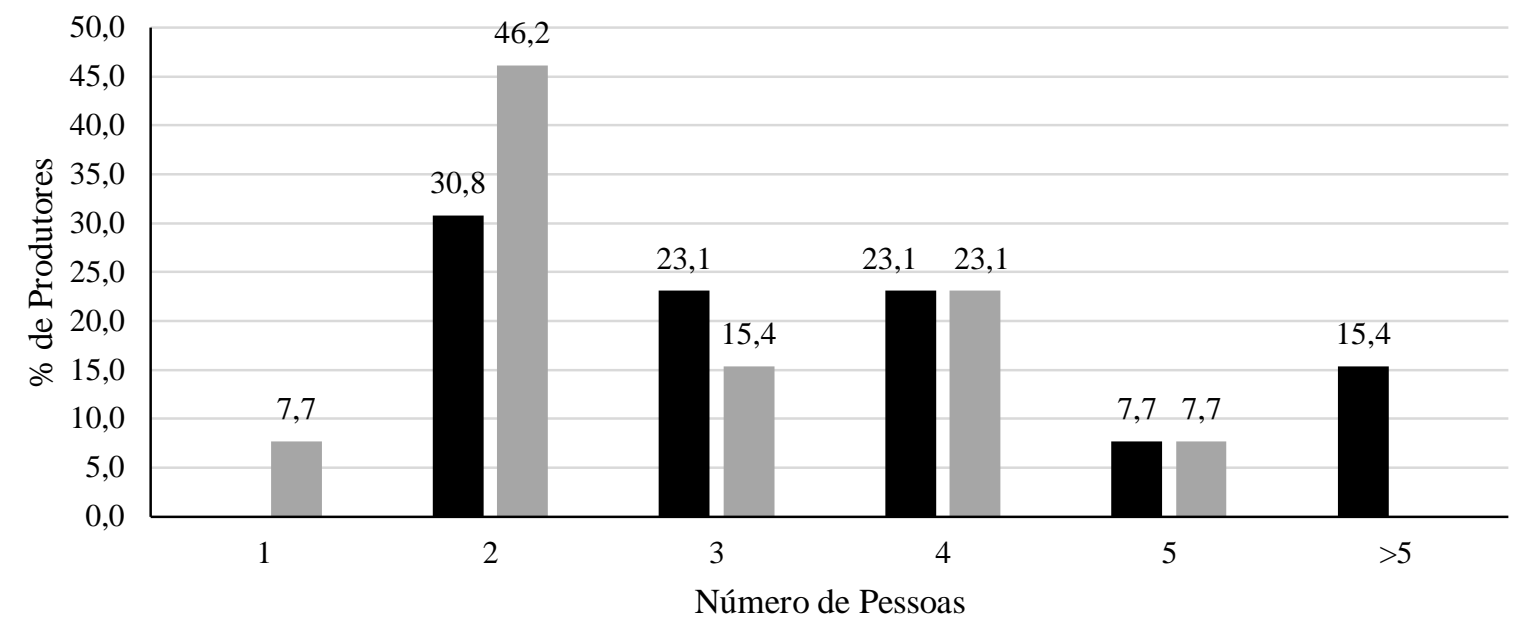

— Total de pessoas que trabalha na propriedade $\square$ Total de pessoas da família que trabalha na propriedade

FONTE: Os autores (2017).

Quando se compara o total de pessoas que trabalham na propriedade e a quantidade de pessoas que são da família, observa-se que há predominância do trabalho familiar, um dos requisitos para serem enquadrados na categoria de agricultores familiares, como já visto. Esse fato torna-se mais evidente quando se observa que apenas 38,5\% das famílias possuem uma ou duas pessoas que exercem trabalho ou possuem renda externa à propriedade. Portanto, a predominância da mão de obra familiar na agricultura orgânica se torna um ponto positivo, pois segundo Moraes e Oliveira (2017, p. 24), a "agricultura orgânica é um sistema de produção intensivo no uso de mão de obra, fator abundante na agricultura familiar e que tende a gerar economicidade".

Em relação à contratação de mão de obra, constatou-se que 30,8\% não utilizam qualquer tipo de mão de obra de terceiros. Já entre os 69,2\% que disseram utilizar mão de obra externa, 55,6\% afirmaram que contratam diarista, mas somente em épocas de maior demanda de serviços, e apenas $11,1 \%$ relataram que possuem empregado permanente, além de pagar diarista eventualmente. Há também 33,3\% que mencionaram utilizar o sistema de parceria. Segundo Nasrallah (2016), parceria é a conjugação de esforços entre produtores rurais, em que o proprietário da terra se junta a outro 
produtor com objetivo de explorar a área para fins agrícolas. A partir dessas informações, observa-se que a maioria dos produtores se enquadra também neste item como agricultores familiares, pois utilizam mão de obra de terceiros esporadicamente.

Cochev et al. (2014), em pesquisa realizada em Alta Floresta - MT sobre a caracterização dos agricultores olerícolas em sistema de produção agroecológico e orgânico, identificaram que apenas 15,6\% dos agricultores contratavam diaristas ou empregados fixos, pois o alto custo de manutenção da terra implica na inviabilidade da contratação de serviços de terceiros. Portanto, o fato dos produtores de orgânicos do Território Noroeste Paulista precisarem contratar mão de obra externa à família pode estar impactando negativamente na lucratividade, especialmente para aqueles que possuem produção em menor escala.

Quanto à área trabalhada pelos produtores de orgânicos (ou transição) do Território Noroeste Paulista, verificou-se que 53,8\% das propriedades possuem até 10 hectares, 30,8\% de 11 a 20 hectares e as demais $(15,4 \%)$ apresentam mais de 20 hectares. Dentre os municípios onde foi realizada a pesquisa, o menor módulo fiscal é de 26 hectares (BRASIL, 2013), portanto, mais de 80\% dos agricultores pesquisados possuem menos de um módulo fiscal. Uma área menor do que o módulo fiscal pode indicar que a terra disponível é insuficiente para promover o bem-estar e desenvolvimento de uma família, considerando o tipo de produção predominante. Mas como a agricultura orgânica é uma forma diferenciada e mais intensiva de produção, esse fator possivelmente não é limitante.

A informação sobre o tempo que o produtor possui a propriedade ou trabalha no campo permite visualizar a experiência dele com a terra e a agricultura. A maioria $(53,8 \%)$ tem até 10 anos de experiência, enquanto 23,1\% estão no trabalho agropecuário por um período de 11 a 20 anos, e os demais (também 23,1\%) estão há mais de 30 anos neste tipo de trabalho.

Diante disso, buscou-se também saber há quanto tempo esses produtores trabalham com orgânicos (ou iniciaram a transição). Verificou-se que quase a totalidade possui uma inserção recente nesse ramo, pois $84,7 \%$ dos entrevistados têm até 5 anos que trabalham com orgânicos e os outros dois produtores (15,4\%) possuem 7 e 8 anos de experiência com orgânicos (Figura 3).

Nogueira et al. (2018), em pesquisa realizada no Paraná sobre leite orgânico, identificaram também que o tempo dedicado pelos produtores de leite à atividade orgânica variava de 1,5 a 8 anos, com uma média de 5 anos. A expansão recente da agricultura orgânica no Brasil, que quase triplicou o número de produtores (VELLEDA, 2017), faz com que grande parte dos grupos tenha poucos anos de experiência nesse sistema de produção.

Os resultados referentes à experiência dos agricultores pesquisados indicam que a maioria dos produtores possui um tempo relativamente pequeno de experiência com agricultura e menor ainda 
em sistemas orgânicos de produção. De modo geral, os produtores do Território ainda estão adquirindo conhecimento sobre o cultivo de orgânicos e também em relação à comercialização, pois a feira de produtos orgânicos foi instalada somente em 2017 em Jales.

FIGURA 3 - DISTRIBUIÇÃO PERCENTUAL DOS AGRICULTORES PESQUISADOS EM FUNÇÃO DO TEMPO (ANOS) QUE TRABALHAM COM ORGÂNICOS NO TERRITÓRIO NOROESTE PAULISTA

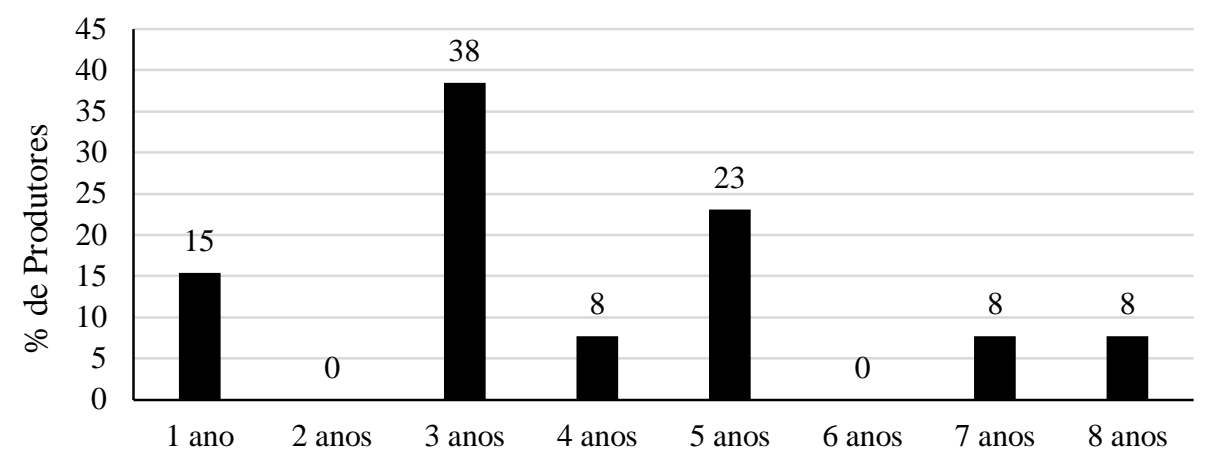

FONTE: Os autores (2017).

Os produtores revelaram que as razões que os levaram a produzir orgânicos foram: a preocupação com a saúde, tanto deles como a dos consumidores; o fato de não precisar trabalhar com agrotóxicos (que também se vincula à questão da saúde); o retorno financeiro (lucrar mais, por ser um produto diferenciado); a qualidade de vida da família; os cursos oferecidos pela CATI (Coordenadoria de Assistência Técnica e Integral) e SENAR (Serviço Nacional de Aprendizagem Rural).

Quanto aos principais produtos orgânicos produzidos em seus estabelecimentos, os agricultores mencionaram o tomate (61,5\% dos pesquisados), a alface $(46,2 \%)$, a abóbora (38,5\%) e o pepino $(30,8 \%)$, entre outros (Figura 4$)$.

No total foram citados 16 produtos com predomínio das olerícolas, mas também há agricultores que cultivam algumas frutas (banana e maracujá) e grãos (milho e feijão). Como já mencionado, dentre os principais produtos orgânicos do Brasil estão as olerícolas e frutas (ORGANICSNET, 2015). 


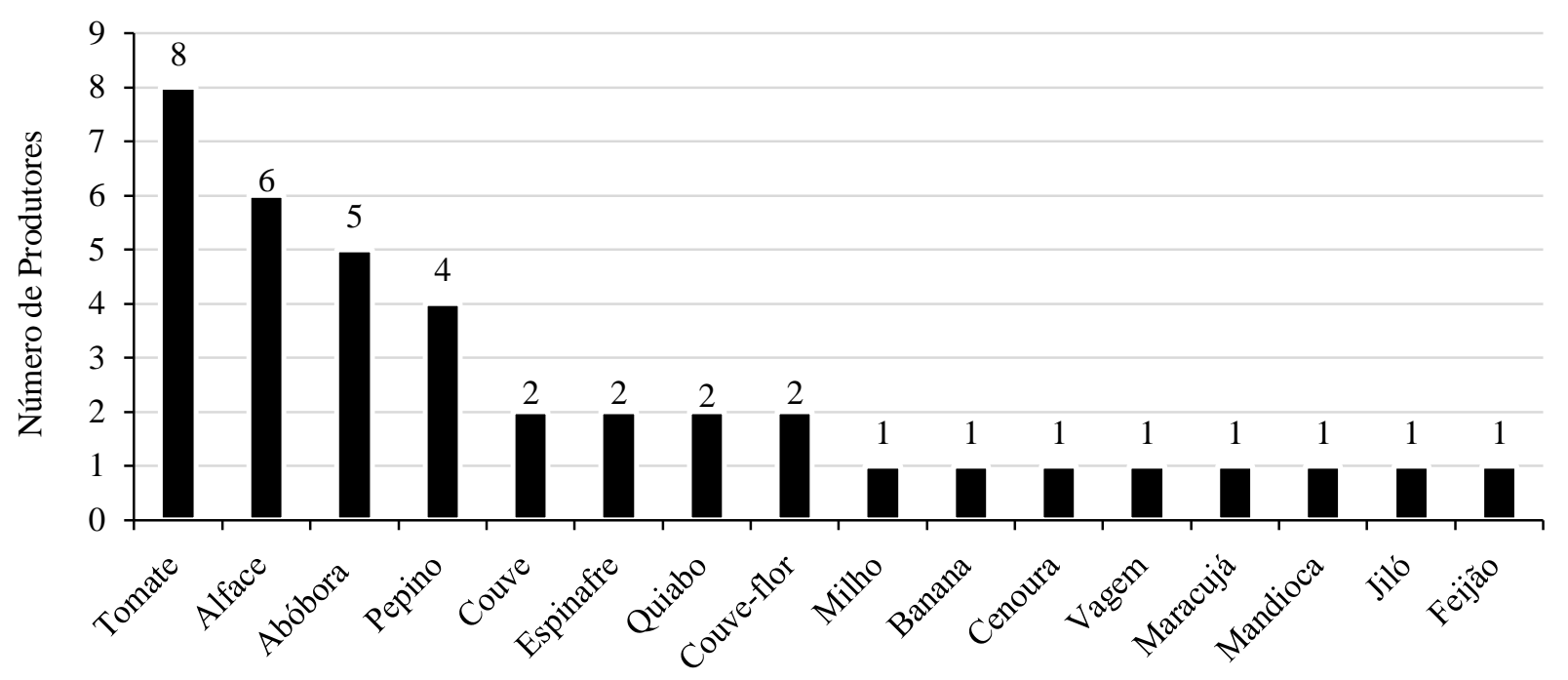

FONTE: Os Autores (2017).

Barbé (2009) destaca que a diversidade na produção de alimentos orgânicos geralmente é uma característica da produção agroecológica, pois essa diversidade contribui para um melhor equilíbrio do sistema e permite a eliminação do uso de produtos químicos. Para Assis (2005, p. 14), “a agricultura orgânica caracteriza-se pela diversificação e integração da produção interna, sendo o termo orgânico originário da ideia de que a unidade de produção funcione como um organismo vivo". Ehlers (2017) também destaca que a diversificação de culturas é uma aptidão da agricultura familiar. Sendo assim, a diversidade de atividades funciona como uma estratégia para a agricultura familiar, pois visa reduzir riscos de perdas totais, racionalizando o uso da mão de obra e extraindo o máximo de proveito da interação em diversas culturas e criações (FUNK, 2008).

A certificação orgânica é uma estratégia para o mercado de produtos orgânicos, pois permite ao agricultor diferenciar seu produto, obter melhor remuneração e ainda protege os consumidores de possíveis fraudes (NEVES; CASTRO, 2007). Por outro lado, os sistemas de certificação por auditoria possuem um custo relativamente alto (BRASIL, 2007), considerando o pequeno volume de produção de parte dos agricultores que adotam sistemas de produção orgânicos.

Entre os produtores pesquisados, $69,2 \%$ possuem certificação, enquanto os demais $(30,8 \%)$ estão em processo de transição ou não possuem ainda o selo, mas estão buscando a certificação participativa. De acordo com a Fundação Internacional para a Agricultura Orgânica (2016), o sistema participativo constitui na organização de um grupo de pequenos produtores que visam à certificação, 
em que a fiscalização não é realizada por terceiros e sim por membros do próprio grupo, o que, na avaliação dos produtores, torna o processo um pouco menos oneroso. Dos produtores certificados, sete $(78 \%)$ disseram ser por meio da OIA (Organização Internacional Agropecuária) e dois (22\%) pela IBD (Associação de Certificação Instituto Biodinâmico). Essa diferença de adesão entre as certificadoras deve-se ao preço da adesão, pois muitos produtores relataram que via IBD é mais cara, porém permite exportar os produtos para outros países.

Quanto à área certificada, constatou-se que 61,5\% possuem até 5 hectares, 30,8\% de 6 a 10 hectares e somente 7,7\% (um produtor) mais de 10 hectares. Quando somados todos os hectares certificados, tem-se o total de 57,4ha. Observa-se que a quantidade é incipiente, pois se trata de uma forma de cultivo que é nova no Território Noroeste Paulista, ao menos na forma certificada. Cabe ressaltar, no entanto, que muitos produtores não certificam a propriedade inteira, pois esse procedimento eleva o preço e, consequentemente, o custo de produção.

Dados divulgados pelo FiBL e a IFOAM - Organics International (2018) mostram que o Brasil possui 1.188.254 hectares destinados à produção de orgânicos e se forem considerados os dados do MAPA (BRASIL, 2020), que registra 21.144 agricultores orgânicos, tem-se uma média aproximada de 56,19 hectares. Embora se deva considerar que algumas culturas, como a cana-de-açúcar, aumentam a área média brasileira, cabe destacar que a área certificada pelos produtores pesquisados é pequena.

Um aspecto importante para consolidar as vendas dos produtos orgânicos é a regularidade da oferta. Todos os produtores disseram que produzem o ano todo, pois possuem irrigação e sistema de cultivo protegido, como as casas de vegetação, o que permite manter a produção. Quanto à forma de comercialização, todos os produtos são vendidos na forma in natura, pois para qualquer processamento é necessária certificação específica.

O Programa Nacional de Alimentação Escolar (PNAE), a partir de 2010, tonou-se um dos instrumentos do governo federal com o intuito de facilitar a comercialização dos agricultores familiares. Este programa abrange o Brasil todo e possui a função de suprir as necessidades escolares, visando hábitos alimentares saudáveis, desenvolvimento, crescimento, aprendizagem e rendimento escolar. As diretrizes do PNAE, estabelecidas pela Lei 11.947/2009 e pela Resolução/CD/FNDE nº 38 , de julho de 2009, determinam que no mínimo $30 \%$ do total de recursos repassados pelo Fundo Nacional de Desenvolvimento da Educação (FNDE) para a alimentação escolar sejam destinados preferencialmente a compras de alimentos orgânicos, oriundos da agricultura familiar, local, regional ou nacional (SILVERIO, 2013). 
No caso de aquisição de alimentos orgânicos via PNAE, a entidade executora (governo estadual ou municipal) deverá realizar uma pesquisa de preço e caso isso seja impossível, poderá acrescer em até $30 \%$ em relação aos preços estabelecidos para produtos convencionais, pois, em princípio, os preços de aquisição de produtos pelo PNAE têm como referência aqueles praticados no âmbito do Programa de Aquisição de Alimentos (PAA), conforme estabelecido na Lei 12.512, de 14 de outubro de 2011, e em alterações posteriores (BRASIL, 2011).

Em relação a possíveis formas de organização para realização da comercialização em conjunto, 69\% (nove) dos produtores disseram que participam de alguma articulação neste sentido. Destes que participam, sete (78\%) mencionaram vender em grupo informal, no caso se trata da Feira de Orgânicos de Jales; um produtor (11\%) citou que vende em conjunto com parentes e um outro afirmou comercializar por meio de associação, cooperativa e grupo informal ao mesmo tempo. É importante destacar que alguns produtores disseram que não vendem em conjunto com outros produtores porque ainda estão em processo de transição e necessitam da certificação para adotar essa prática.

A constituição do grupo de agricultores orgânicos e a estruturação da feira foram processos articulados pelo Colegiado do Território Noroeste Paulista, com apoio do Núcleo de Extensão em Desenvolvimento Territorial (NEDET) da Unesp de Ilha Solteira, e como parte da política de desenvolvimento territorial, então vigente em nível federal. Além da atuação conjunta na feira, os agricultores têm se articulado para a realização de cursos de formação que se iniciaram na época do NEDET, mas que continuaram via parceria com outros atores sociais.

Quando questionados, especificamente, sobre o destino da produção, 84,6\% do total dos pesquisados citaram as vendas diretas para consumidor final, 38,5\% afirmaram vender para intermediários (atravessadores), 30,8\% indicaram outros agentes, como por exemplo, o comércio varejista e os restaurantes, e 7,7\% (um produtor) para órgãos públicos (Figura 5). Os agricultores enumeraram todos os canais de comercialização para os quais destinavam a produção, sendo que $76,9 \%$ utilizavam mais de uma forma de comercialização. 


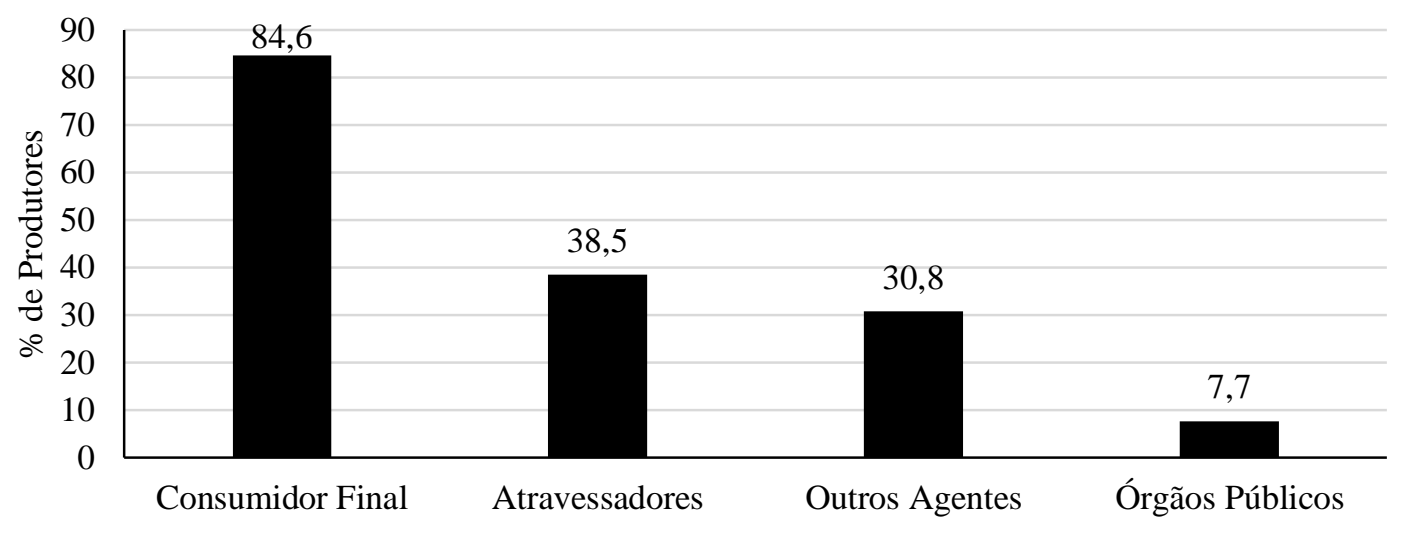

FONTE: Os autores (2017).

NOTA: Valores com repetição. Produtores podiam citar mais de uma forma de comercialização.

De acordo com a pesquisa realizada por Barbé (2009, p. 42) em Campos dos Goytacazes, " $80 \%$ dos produtores vendem seus produtos em feiras, $40 \%$ nas feiras e restaurantes e $10 \%$ fazem a venda para o atravessador". Na pesquisa executada por Finatto e Corrêa (2010), o PAA se constituía no principal meio de comercialização de produtos orgânicos dos produtores do município de Pelotas (RS), enquanto as feiras se posicionavam em segundo lugar.

No caso da venda para órgãos públicos, a única produtora disse entregar para o PNAE, no entanto, vale ressaltar que segundo ela, a prefeitura do município onde entrega seus produtos não remunera de forma diferenciada os produtos orgânicos, ou seja, paga o mesmo valor pago pelos convencionais. Como já mencionado, a Lei 12.512 possibilita, mas não garante, o pagamento de um acréscimo de $30 \%$ ao preço dos produtos agroecológicos ou orgânicos (BRASIL, 2011). A agricultora também revelou que neste tipo de comercialização há a garantia de recebimento, mas, em contrapartida, tem ocorrido a falta de cumprimento de prazos de pagamento.

Diante da constatação da relevância da venda direta, foi perguntado aos agricultores sobre as vantagens e desvantagens da comercialização realizada aos consumidores finais. Quanto às vantagens, mencionaram: lucratividade maior, pagamento à vista, venda rápida, não ter devolução de produto e eliminação dos atravessadores (o que significa também ter maior margem de lucro). Já como desvantagens, apontaram: irregularidade das vendas ("há dias que não vende bem"); a necessidade de dedicação de tempo para esta atividade; o fato de demandar organização quanto às embalagens e ao transporte; a falta de informação por parte dos consumidores sobre o que são os 
orgânicos; a falta de parcerias entre os agricultores; e a dificuldade de cobrar dos consumidores o preço real equivalente a um produto orgânico.

Quanto à venda realizada para os atravessadores e outros agentes, 78\% dos produtores relataram que a negociação é realizada por telefone, enquanto os demais (22\%) disseram que vão até a empresa do comprador. Em relação a utilização de contrato durante a negociação, $89 \%$ afirmaram que não utilizam esse expediente, o que deixa os agricultores mais vulneráveis em caso de descumprimento do acordo.

A forma de pagamento predominante é a prazo, citada por $67 \%$ dos produtores, mas $22 \%$ mencionaram receber à vista e 11\% afirmaram combinar as duas formas. Quando vendem com prazo para o pagamento, a grande maioria (71\%) citou o período de 31 a 60 dias e os demais (29\%) até 30 dias. De modo geral, os agricultores não recebem cheque e nem utilizam contrato como forma de garantia de pagamento, portanto, as negociações são realizadas com base na confiança, mas alguns produtores revelaram já ter levado calotes, com prejuízos irreparáveis.

Centeno, Tondato e Nakao (2016), em pesquisa sobre a comercialização de laranja no município de Vitória Brasil - SP (pertencente ao Território Noroeste Paulista), também detectaram que a maior parte dos produtores vendem a prazo e não recebem cheque como garantia de pagamento, o que evidencia que se trata de uma prática frequente de negociação entre produtores e compradores da região, mas que embute ameaças ao equilíbrio financeiro dos agricultores.

Avaliar se a renda bruta total da família é obtida por meio de atividades agropecuárias do estabelecimento permite verificar se os agricultores se caracterizam como pertencentes à agricultura familiar, assim como o grau de dependência da atividade agropecuária. Do total pesquisado, 84,6\% dos agricultores afirmaram possuir mais da metade da renda bruta total obtida da propriedade, enquanto apenas dois agricultores $(15,4 \%)$ obtém até 50\% da renda da propriedade (Figura 6). 


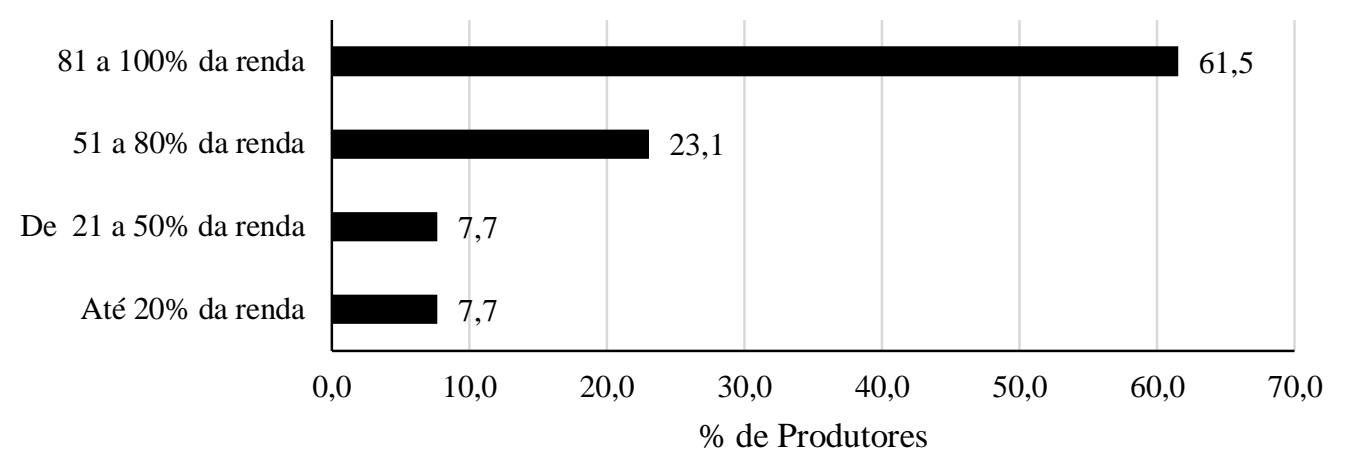

FONTE: Os autores (2017).

De modo geral, mesmo quando presente, a renda externa à propriedade é pouco relevante na composição da renda familiar. Em um dos casos, a renda externa não agrícola não significa pluriatividade, pois é proveniente de aposentadoria, enquanto nas outras situações trata-se de empregos na área urbana (1 auxiliar de vendas, 1 motorista e 2 servidores públicos, em que cada família possui apenas um membro que trabalha fora).

Werlang e Mendes (2016) interpretam que a pluriatividade leva o pequeno agricultor a se distanciar da sua característica principal (produzir alimentos para o seu sustento), com o objetivo do assalariamento. Mas outros autores, como Carneiro (2006), consideram que as rendas não agrícolas e mesmo a pluriatividade (que segunda a autora é a combinação, por membros de uma mesma família, de renda de trabalhos agrícolas e não agrícolas) podem inserir-se como mais uma das estratégias de reprodução social da agricultura familiar, visando adaptar-se às mudanças recentes no meio rural. Este é o caso da maioria dos agricultores pesquisados que exercem atividades externas ao estabelecimento, mas como uma estratégia de manutenção da família no estabelecimento rural familiar.

Quando questionados sobre a faixa de renda monetária bruta obtida na propriedade (Figura 7), apenas um produtor afirmou que é até 1 salário mínimo (em 2017, correspondia a $\mathrm{R} \$ 938,00$ ). A maioria (53,8\%) informou o rendimento na faixa de mais de 1 a 3 salários mínimos $(\mathrm{R} \$ 938,01$ a $\mathrm{R} \$$ 2.811,00); 23,1\% enquadraram-se na faixa de mais de 3 a 6 salários ( $\mathrm{R} \$ 2.812,01$ a $\mathrm{R} \$ 5.622,00)$; e 15,4\% dos agricultores avaliaram sua renda, proveniente do estabelecimento, em mais de 9 salários mínimos (mais de $\mathrm{R} \$ 8.434,00$ ). 

SALARIAL FAMILIAR OBTIDA POR PROPRIEDADE RURAL DO TERRITÓRIO NOROESTE PAULISTA

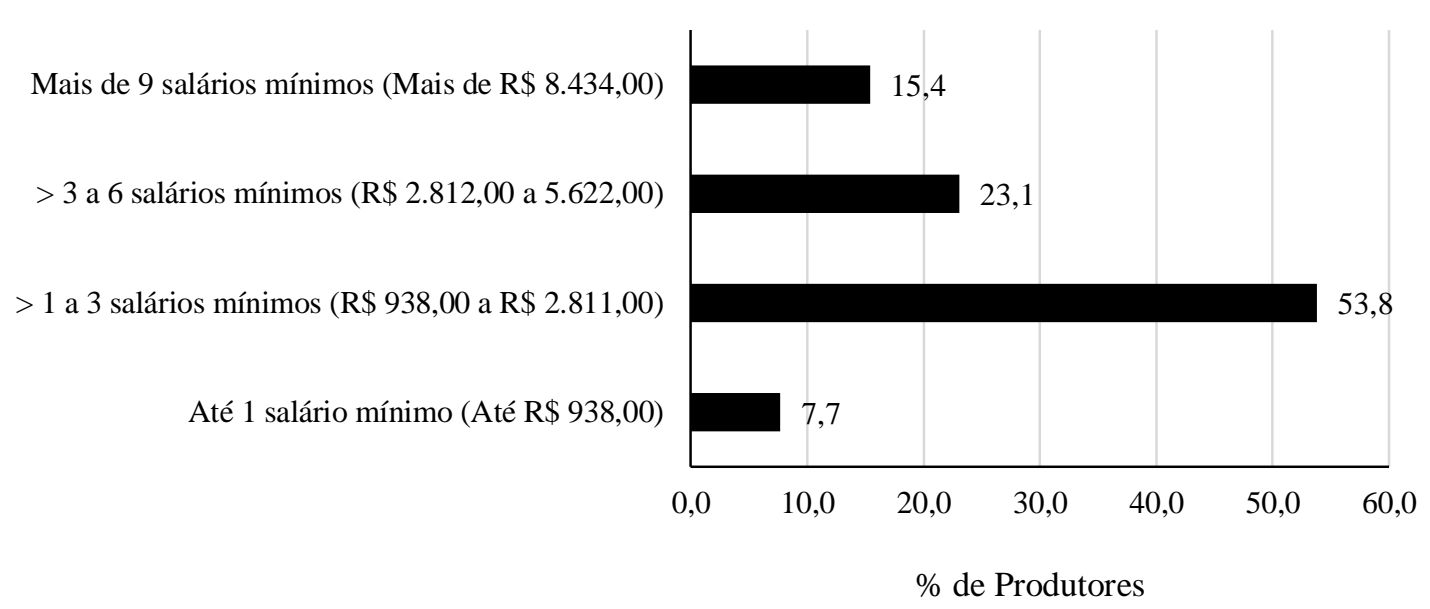

FONTE: Os autores (2017).

Martinelli, Armstrong e Cordeiro (2016) identificaram em sua pesquisa com produtores de orgânicos de Palotina - PR que as famílias cujos membros não trabalham diretamente na agricultura orgânica, ou seja, possuem outros empregos, detém rendas mais elevadas quando comparadas àquelas que vivem exclusivamente dos orgânicos. Ainda de acordo com os autores, 35\% das famílias entrevistadas recebiam mais de cinco salários mínimos e 55\% obtinham em média de 3 a 5 salários mínimos.

Embora no primeiro momento possa parecer que a renda das famílias de Palotina - PR é maior do que a das famílias do Território Noroeste Paulista, no caso de Palotina se trata da renda mensal total, obtida tanto da propriedade quanto externamente; já as famílias do Território Noroeste Paulista indicaram apenas a renda proveniente da propriedade.

\section{Considerações finais}

A análise das características da produção de orgânicos no Território Noroeste Paulista mostrou que esta é composta predominantemente pelo cultivo de olerícolas, realizada por agricultores familiares que têm essa atividade como a principal fonte de renda agropecuária, sendo que a maioria apresenta renda monetária familiar relativamente baixa (embora esta seja desigual no grupo pesquisado). 
A grande maioria (quase 70\%) dos produtores possui certificação orgânica e comercializa parte de sua produção em circuitos curtos, especialmente a venda direta ao consumidor, em feira própria de orgânicos na cidade de Jales, organizada por meio de grupo informal de agricultores, mas uma parte expressiva depende também da venda a intermediários para escoar seus produtos.

Embora o número de agricultores envolvidos na produção orgânica, no referido Território Noroeste Paulista, seja relativamente pequeno, o fato de estarem organizados em um grupo que tem promovido a comercialização direta aos consumidores e atividades de formação técnica dos produtores permite vislumbrar uma perspectiva de ampliação da produção orgânica. No entanto, esses produtores já carecem de reforçar suas estratégias de inserção em circuitos curtos que ampliam a autonomia e, potencialmente, as margens de lucro dos agricultores, embora demandem um esforço maior para realizar mais uma tarefa além da produção agrícola. Nesse sentido, a organização deles para entregar ao PNAE pode ser uma alternativa promissora.

Esta pesquisa, ao contribuir para o conhecimento dos produtores e de suas estratégias de cultivo e comercialização de orgânicos no Território Noroeste Paulista, pode ser um instrumento para auxiliar nas decisões que visem apoiar os agricultores em atividade e/ou para ampliar esse tipo de produção, por meio de políticas públicas locais.

\section{Referências}

ANDRADE, M. M. Introdução à metodologia do trabalho científico. 10. ed. São Paulo: Atlas, 2010.

ANJOS, F. S. O futuro ameaçado: o mundo rural face aos desafios da masculinização, do envelhecimento e da desagrarização. Ensaios FEE, Porto Alegre, v. 26, n. 1, p. 661 - 694, 2005.

ASSIS, R. L. Agricultura orgânica e agroecologia: questões conceituais e processo de conversão. Seropédica: Embrapa Agrobiologia, 2005. (Embrapa Agrobiologia. Documentos, 196). Disponível em: https://www.infoteca.cnptia.embrapa.br/infoteca/bitstream/doc/628360/1/doc196.pdf. Acesso em: 15 mar. 2018.

BARBÉ, L. C. Caracterização de consumidores e produtores dos produtos agroecológicos/orgânicos em Campos dos Goytacazes, RJ. 2009. 64p. Dissertação (Mestrado em Produção Vegetal) - Universidade Estadual do Norte Fluminense Darcy Ribeiro, Campos dos Goytacazes, 2009.

BOURDIEU, P. Coisas ditas. São Paulo: Brasiliense, 1990. 234p. 
BRASIL. Ministério da Agricultura, Pecuária e Abastecimento. Cadeia produtiva de produtos orgânicos. Ministério da Agricultura, Pecuária e Abastecimento, Secretaria de Política Agrícola, Instituto Interamericano de Cooperação para a Agricultura. Brasília: IICA: MAPA/SPA, 2007. Disponível em: http://orton.catie.ac.cr/repdoc/A4931p/A4931p.pdf. Acesso em: 04 set. 2017.

BRASIL. Lei 12.512 de 14 de outubro de 2011. Disponível em: http://www.planalto.gov.br/ccivil_03/_Ato2011-2014/2011/Lei/L12512.htm. Acesso em: 19 out. 2019.

BRASIL. Instituto Nacional de Colonização e Reforma Agrária. Tabela com módulo fiscal dos municípios. Sistema Nacional de Cadastro Rural. Índices Básicos de 2013. Disponível em: http://www.incra.gov.br/sites/default/files/uploads/estrutura-fundiaria/regularizacao-

fundiaria/indices-cadastrais/indices_basicos_2013_por_municipio.pdf. Acesso em: 04 set. 2017.

BRASIL. Ministério do Desenvolvimento Agrário - MDA. Orientações gerais para a elaboração e qualificação do PTDRS - Programa Desenvolvimento Sustentável de Territórios Rurais. Brasília, 2009. Disponível em: file://C:/Users/Usuario/Downloads/GUIA_DO_PTDRS__2.a_versao_FINAL.pdf. Acesso em: 20 dez. 2016.

BRASIL. Ministério do Desenvolvimento Agrário - MDA. Secretaria de Desenvolvimento Territorial - SDT. Plano Territorial de Desenvolvimento Rural Sustentável. Território Noroeste Paulista (SP) - São Paulo: novembro de 2010. Disponível em: http://sit.mda.gov.br/download/ptdrs/ptdrs_qua_territorio151.pdf. Acesso em: 04 set. 2017.

BRASIL. Ministério da Agricultura, Pecuária e Abastecimento. Cadastro Nacional de Produtores Orgânicos, 2020. Disponível em: https://www.gov.br/agricultura/ptbr/assuntos/sustentabilidade/organicos/cadastro-nacional-produtores-organicos. Acesso em: 03 abr. 2020 .

CAMARANO, A. A; ABRAMOVAY, R. Êxodo rural, envelhecimento e masculinização no Brasil: panorama dos últimos 50 anos. Rio de Janeiro, 1999. ISSN 1415-4765. Disponível em: http://repositorio.ipea.gov.br/bitstream/11058/2651/1/td_0621.pdf. Acesso em: 13 mar. 2018.

CARNEIRO, M. J. Pluriatividade da agricultura no Brasil: uma reflexão crítica. In: SCHNEIDER, S. A diversidade da agricultura familiar. Porto Alegre: UFRGS, 2006, p. 165-185.

CARVALHO, R. Jales promove III Seminário de Agricultura Orgânica. Jornal Folha Noroeste. Publicado em: 15/07/2017. Disponível em: http://folhanoroeste.blogspot.com.br/2017/07/jalespromove-iii-seminario-de.html. Acesso em: 04 set. 2017.

CENTENO, D. C.; TONDATO, C.; NAKAO, A. H. Comercialização da laranja no município de Vitória Brasil - SP. Simpósio Nacional de Tecnologia em Agronegócio. 06 a 08 de outubro de 2016. Disponível em: http://www.fatecjales.edu.br/sintagro/images/anais/tematica6/comercializacao-dalaranja-no-municipio-de-vitoria-brasil-sp.pdf. Acesso em: 04 abr. 2018.

COCHEV, J. S.; NEVES, S. M. A. S.; SEABRA JUNIOR, S; NEVES, R. J.; DASSOLLER, T. F.; CAIONI, C. Caracterização dos agricultores olerícolas com sistema de produção agroecológico e sistema orgânico em Alta Floresta/MT. Cadernos de Agroecologia, v. 9, n. 4, 2014. Disponível em: 
http://revistas.aba-agroecologia.org.br/index.php/cad/article/view/16383/10330. Acesso em: 02 abr. 2018.

CRESWELL, J. W. Projeto de pesquisa: métodos qualitativo, quantitativo e misto. 3. ed. Porto Alegre: Artmed, 2010.

EHLERS, E. O que é agricultura sustentável? São Paulo: Brasiliense, 2017. E-book. Disponível em: https://books.google.com.br/books?hl=pt-

$\mathrm{BR} \& 1 \mathrm{r}=\& \mathrm{id}=\mathrm{smgvDwAAQBAJ} \& \mathrm{oi}=\mathrm{fnd} \& \mathrm{pg}=\mathrm{PT} 2 \& \mathrm{dq}=\mathrm{impactos}+\mathrm{da}+$ agricultura + convencional $\& \mathrm{o}$ ts=lkaw-YGfYG\&sig=alhxJLRVf_0AjAS3u-2Exg2eK

$\mathrm{M} \# \mathrm{v}=$ onepage $\& \mathrm{q}=\mathrm{impactos} \% 20 \mathrm{da} \% 20$ agricultura $\% 20$ convencional $\& \mathrm{f}=$ false. Acesso em: 05 mar. 2018.

FINATTO, R. A.; CORRÊA, W. K. Desafios e perspectivas para a comercialização de produtos de base agroecológica - O caso do município de Pelotas/RS. Revista Brasileira de Agroecologia, Porto Alegre, v. 5, n. 1, p. 95-105, 2010. ISSN: 1980-9735. Disponível em: file:///C:/Users/Usuario/Downloads/9669-1-41175-1-10-20100320.pdf. Acesso em: 02 abr. 2018.

FUNK, F. Agricultura familiar diversificada e qualidade de vida: o caso do município de São Pedro do Butiá - Rio Grande do Sul. 2008, 197f. Dissertação (Mestrado em Desenvolvimento Regional) Universidade de Santa Cruz do Sul - UNISC, 2008.

GASQUES, J. G.; BACCHI, M. R. P.; RODRIGUES, L.; BASTOS, E. T.; VALDES, C. Produtividade da agricultura brasileira: a hipótese da desaceleração. In: VIEIRA FILHO, J. E. R.; GASQUES, J. G. (Orgs.). Agricultura, transformação produtiva e sustentabilidade. Brasília: Ipea, 2016. p. 143-163.

GIL, A. C. Métodos e técnicas de pesquisa social. 6. ed. São Paulo: Atlas, 2008.

INSTITUTO BRASILEIRO DE GEOGRAFIA E ESTATÍSTICA - IBGE. Censo Agropecuário, 2006. Agricultura Familiar, Brasil. Disponível em: https://www.ibge.gov.br/estatisticasnovoportal/economicas/agricultura-e-pecuaria/9827-censo-

agropecuario.html?edicao=9829\&t=resultados. Acesso em: 08 nov. 2017.

INSTITUTO BRASILEIRO DE GEOGRAFIA E ESTATÍSTICA - IBGE. Síntese de indicadores sociais, 2014. Disponível em: http://www.ibge.gov.br/home/estatistica/populacao/condicaodevida/indicadoresminimos/sinteseindi csociais2014/default_tab_ods.shtm. Acesso em: 06 set. 2017.

LIMA, E. C. S. Estudo dos efeitos socioambientais sobre a agricultura familiar da expansão canavieira no noroeste do estado de São Paulo. 116f. Tese (Meio Ambiente e Desenvolvimento Regional), Programa de Pós-Graduação em Meio Ambiente e Desenvolvimento Regional da Universidade Anhanguera - Uniderp, Campo Grande, MS, 2016.

MARCONI, M. A.; LAKATOS, E. M. Fundamentos de metodologia científica. 7. ed. São Paulo: Atlas, 2010.

MARTINELLI, J. V.; ARMSTRONG, C. J.; CORDEIRO, J. Aspectos socioeconômicos da produção de alimentos orgânicos em Palotina PR. Revista Cultivando o Saber, v. 9, n. 3, p. 318-336, 2016. 
Disponível em: https://www.fag.edu.br/upload/revista/cultivando_o_saber/580524c49c87c.pdf. Acesso em: 04 abr. 2018.

MORAES, M. D.; OLIVEIRA, N. A. M. Produção orgânica e agricultura familiar: obstáculos e oportunidades. Revista Desenvolvimento Socioeconômico em Debate - RDSD, v. 3, n. 1, 19-37, 2017. Disponível em: http://periodicos.unesc.net/RDSD/article/view/3372/3465. Acesso em: 02 abr. 2018.

NASRALLAH, A. Planejamento no agronegócio: parceria rural $\mathrm{x}$ arrendamento rural. Publicado em: 16/05/2016. Disponível em: http://tributarionosbastidores.com.br/2016/05/agro/. Acesso em: 04 set. 2017.

NEVES, M. F.; CASTRO, L. T. Marketing e estratégia em agronegócios e alimentos. São Paulo: Atlas, 2007.

NOGUEIRA, C. R.; BÁNKUTI, S. M. S; LOURENZANI, A. E. B. S; BÁNKUTI, F. I.; LOURENZANI, W. F. Coordenação de sistemas agroalimentares diferenciados: um estudo sobre o leite orgânico no Paraná. Revista Gestão \& Regionalidade, v. 34, n. 100, p. 74-91, 2018. Disponível em: http://seer.uscs.edu.br/index.php/revista_gestao/article/view/3696/2367. Acesso em: 02 abr. 2018.

ORGANICSNET. Agricultores familiares receberão certificação orgânica. Publicado em: 04/03/2015. Disponível em: http://www.organicsnet.com.br/2015/03/agricultores-familiaresreceberao-certificacao-organica/. Acesso em: 04 set. 2017.

PLURAL - Cooperativa de Consultoria, Pesquisa e Serviços. Plano Territorial de Desenvolvimento Rural Sustentável Território Noroeste Paulista (SP). São Paulo: PLURAL/MDA, 2011.

REIS, E. A.; REIS, I. A. Análise descritiva de dados. Relatório Técnico do Departamento de Estatística da UFMG, 2002. Disponível em: www.est.ufmg.br Acesso em: 18 abr. 2018.

RESEARCH INSTITUTE OF ORGANIC AGRICULTURE - FIBL. INTERNATIONAL FEDERATION OF ORGANIC AGRICULTURE MOVEMENTS - IFOAM - Organics International. Dados sobre a área orgânica no mundo. 2020. Disponível em: https://statistics.fibl.org/world/areaworld.html?tx_statisticdata_pi1\%5Bcontroller\%5D=Element2Ite m\&cHash=f367262839ab9ca2e7ac1f333fbb1ca2. Acesso em: 03 abr. 2020.

RESEARCH INSTITUTE OF ORGANIC AGRICULTURE - FIBL. The World of Organic Agriculture 2017. February 9, 2017. Disponível em: http://www.fibl.org/fileadmin/documents/en/news/2017/mr-world-organic-agriculture-2017english.pdf. Acesso em: 22 nov. 2017.

SANT'ANA, A. L. Estratégias dos agricultores familiares: entre a moldagem da intensificação produtiva e a construção de formas diferenciadas de comercialização. Retratos de Assentamentos, v. 14, p .283 - 304, 2011.

SANT'ANA, A. L.; SILVA, F. C.; SANTANA, D. Z. Sistemas de produção dos agricultores familiares da microrregião de Jales (SP, Brasil) e as políticas públicas. In: CONGRESO DE LA 
ASOCIACIÓN LATINOAMERICANA DE SOCIOLOGÍA RURAL, 9, 2014, Cidade do México. Anais... Cidade do México: Alasru, 2014. p. 01- 25.

SILVA, F. D.; RIBEIRO, M. L.; DUVAL, H. C.; FERRANTE, V. L. S. B. As dificuldades de "passar o bastão": perspectiva da sucessão da propriedade entre produtores de comunidades rurais do município de Campo Gerais - MG. Retratos de Assentamentos, v. 20, n. 2, p. 240-261, 2017. Disponível em: http://www.retratosdeassentamentos.com/index.php/retratos/article/view/288/260. Acesso em: 02 abr. 2018.

SILVERIO, G. A. Alimentos orgânicos na alimentação escolar: perspectivas de atores sociais em municípios de Santa Catarina. 2013. 208f. Dissertação (Mestrado em Nutrição) - Universidade Federal de Santa Catarina, Centro de Ciências da Saúde. Florianópolis, 2013. Disponível em: $<$ https://repositorio.ufsc.br/bitstream/handle/123456789/107544/320909.pdf?sequence=1\&isAllowe $\mathrm{d}=\mathrm{y}>$. Acesso em: 04 set. 2017.

TELLES, T. S.; COSTA, G. V.; BACCHI, M. D.; LAURENTI, A. C. Evolução da população rural ocupada nas Grandes Regiões do Brasil entre 2001 e 2009. Interações (Campo Grande), v. 18, n. 1, p. 17-26, Campo Grande, 2017. http://dx.doi.org/10.20435/1984-042x-2017-v.18-n.1(02). Disponível em: http://www.scielo.br/scielo.php?pid=S151870122017000100017\&script=sci_arttext. Acesso em: 15 mar. 2018.

VELLEDA, L. Agricultura familiar e reforma agrária são os maiores produtores de orgânicos no Brasil. Publicado em: 23/03/2017. Disponível em: http://www.redebrasilatual.com.br/saude/2017/03/agriculturafamiliar-e-reforma-agraria-sao-os-maiores-produtores-de-organicos-no-brasil. Acesso em: 04 set. 2017.

VERGARA, S. C. Projetos e relatórios de pesquisa em administração. 13. ed. São Paulo: Atlas, 2010.

WERLANG, R.; MENDES, J. M. R. Pluriatividade no meio rural: flexibilização e precarização do trabalho na agricultura familiar. Em Pauta, Rio de Janeiro, v. 14, n. 38, p. 140-163, 2. sem. 2016. Publicado em: 22/05/2017. Disponível em: http://www.epublicacoes.uerj.br/index.php/revistaempauta/article/view/27857 Acesso em: 22 out. 2017.

Artigo recebido em 08/04/2020. Aceito para publicação em 24/07/2020. 